\title{
ACERCA DE LA GÉNESIS DE UN RASGO SINTÁCTICO DEL ESPAÑOL ANTILLANO (LA NO TRANSPOSICIÓN DEL SUJETO PRONOMINAL EN ORACIONES INTERROGATIVAS)
}

\author{
Germán de Granda \\ Universidad de Valladolid
}

En un reciente trabajo ${ }^{1}$, a propósito del fenómeno sintáctico caribeño de la no inversión de la posición del pronombre sujeto en oraciones interrogativas directas introducidas por pronombres o adverbios ${ }^{2}$, mi querido maestro Rafael Lapesa expresaba, de acuerdo en ello con los principios metodológicos que han caracterizado, desde su inicio, a la llamada Escuela Española de Lingüistica inspirada en el pensamiento de Menéndez Pidal y en relación con este tema concreto, la necesidad de basar la dilucidación de su (o sus) factores causales en el análisis de materiales de indole diacrónica, ya que "sólo a la luz que arroje tal examen podrá dictaminarse acerca de las influencias... alegadas" sobre su génesis ${ }^{3}$.

Llevando a la práctica (si bien en dimensiones muy modestas) el desideratum expresado por Lapesa, me ha sido dado encontrar, como lo expongo

1 * La interpolación del sujeto en las oraciones interrogativas», en prensa en Actas del II Congreso Internacional de Historia de la Lengua Española.

2 Sobre la regla de postposición del sujeto pronominal, en este caso, en el español estándar véase F. D'Introno, Sintaxis y semántica en la lingüística generativa, Madrid, 1985, pág. 116.

3 Coincide plenamente el enfoque teórico de la Escuela Española de Lingülstica respecto a la necesidad de insertar los datos derivados de investigaciones sincrónicas dentro de su adecuado contexto diacrónico, único que puede dar sentido histórico (y, por lo tanto, fundamentación correctamente explicativa) a los problemas considerados, con los puntos de vista metodológicos expuestos, recientemente, por E. Coseriu en su trabajo «Vom Primat der Geschichte», en Sprachwissenschaft, 5, 1980, págs. 125-145 y por Guillermo L. Guitarte en el suyo titulado «Dialecto, español de América e historia en Coseriu», en Harald Thun (ed.), Energeia und Ergon, 2, Tübingen, 1988, págs. 487-500. 
en otro lugar ${ }^{4}$, un caso del fenómeno en cuestión en un texto dominicano, manuscrito, del siglo xvin que ya había tenido ocasión de frecuentar, con motivo de diversos rasgos lingüísticos que en él se encuentran, en ocasiones anteriores ${ }^{5}$.

$\mathrm{La}$ consideración detallada de este aislado testimonio, único que, al parecer, escapó a la labor de camuflaje lingüístico ${ }^{6}$ llevada a cabo en el resto de su extenso texto por el autor del mismo, no sólo me ha conducido a postular el empleo del rasgo sintáctico en cuestión por segmentos determinados de la sociedad dominicana ( $y$, probablemente, también de sus homólogas cubana y puertorriqueña) de la décimooctava centuria, sino que, además, me ha llevado a reafirmarme en puntos de vista sostenidos ya por mí previamente (si bien de modo muy rápido y carente de desarrollo) ${ }^{7}$, que afectan a los condicionamientos causales del esquema sintáctico a que nos estamos refiriendo.

En efecto, partiendo de la aplicación al testimonio documental estudiado de conceptos metodológicos delineados, muy acertadamente, por A. Vàrvaro ${ }^{8} \mathrm{y}$, simultáneamente, de la correcta valoración de las circunstancias socioeconómicas que caracterizaron, durante el siglo xvili, al área suroccidental dominicana 9 , llegué a la conclusión, en mi trabajo citado, de que parecía

- «Un rasgo sintáctico caribeño en el español dominicano del siglo xvin (la no inversión del pronombre sujeto en oraciones interrogativas)», en prensa en Anuario de Lingǘstica Hispánica, 7, 1991.

- Cfr. mis trabajos «Dos rasgos dialectales del español dominicano en el siglo xvir»», en Lingüistica Española Actual, 9, 1987, págs. 235-241 y «Algunos rasgos fonéticos del español del área suroccidental dominicana en el siglo xvir», en prensa en Actas del VIII Congreso Internacional de A.L.F.A.L. (Tucumán, 1987).

El texto a que me refiero es Historia de la conquista de la Isla Española de Santo Domingo trasumptada el año de 1762, de que fue autor Luis Joseph Peguero. El manuscrito se encuentra en la Biblioteca Nacional de Madrid. Existe una excelente transcripción del mismo, realizada por Pedro J. Santiago, que fue publicada en 1975 en Santo Domingo dentro de la colección Publicaciones del Museo de las Casas Reales (dos volúmenes).

- Sobre este concepto instrumental, utilizable en la crítica lingüfstica de textos literarios (o semi-literarios) y documentales de otras épocas históricas, véase, últimamente, W. Wolfram, «Re-examining Vernacular Black English», en Language, 66, 1990, págs. 121133 y N. Maynor, *Written records of spoken language: How reliable are they?*, en A. R. Thomas (ed.), Metbods in Dialectology, Philadelphia, 1988, págs. 109-120. En el ámbito hispánico, cfr. María Beatriz Fontanella de Weinberg, *La 'lengua gauchesca' a la luz de recientes estudios de lingülstica histórica», en Filología, 21, 1966, págs. 7-23.

7 En mi trabajo «Situación actual de los estudios lingülsticos afrohispanoamericanos», en Thesaurus, 42, 1987 (pág. 28 de la separata que manejo).

- Cfr. su estudio *La dialettologia e le letterature dialettali: ragioni di un divorziow, en el volumen del autor La parola nel tempo. Lingua, societd e storia, Bolonia, 1984, págs. 233-242. También del mismo A. Vàrvaro, «Considerazioni sul problema del protoromanzon, en Problemi della ricostruzione in Linguistica, Roma, 1977, págs. 143-157.

- Véanse Rubén Silie, Economia, esclavitud y población. Ensayo de interpretación bistorica del Santo Domingo español del siglo XVIII, Santo Domingo, 1976; Roberto 
oportuno deducir, de los datos considerados (y del sentido de los mismos una vez incluidos en su correcto contexto sociohistórico), la existencia de una alta probabilidad de que la no inversión de la posición del pronombre sujeto en oraciones interrogativas del tipo mencionado al comienzo de estas líneas hubiera sido utilizada durante una larga etapa cronológica (quizá abarcadora de la totalidad del periodo colonial antillano) como rasgo, lógicamente estigmatizado, propio de grupos sociológicos, de composición muy mayoritariamente negra, enclavados en los estratos más bajos de las sociedades del Caribe hispánico.

La apreciación conjunta de esta hipótesis que, por otra parte, me pareció estar apoyada, además, por determinados datos encontrados en diferentes manifestaciones (cubanas y puertorriqueñas) de la literatura popular insular del siglo $\mathrm{XIX}^{10}$, y de los datos facilitados por la demografía histórica ${ }^{11} \mathrm{y}$ por la historia social del área ${ }^{12}$ sobre la caracterización racial que debe ser atribuida a los diferentes territorios antillanos hispánicos durante los siglos Xvi-xx me induce, en definitiva, a considerar no sólo como posible sino, incluso, como muy probable la postura teórica expuesta hace ya bastante

Cassá, Historia social y económica de Santo Domingo, Santo Domingo, 1977; M. R. Sevilla Soler, Santo Domingo, tierra de frontera (1750-1800), Sevilla, 1980 y A. Gutiérrez Escudero, Población y economia en Santo Domingo (1700-1746), Sevilla, 1985. Además, claro está, del volumen básico de Frank Moya Pons, Historia colonial de Santo Domingo, Santiago de los Caballeros, 1974.

${ }_{10}$ Me refiero, sobre todo, al denominado teatro bufo cubano (y puertorriqueño) del que se conserva una amplísima colección en la Universidad Central de Las Villas de Santa Clara, Cuba (Fondo Francisco de Paula Coronado), hasta ahora muy poco estudiada por los especialistas. Véase una muestra del mismo en Rine Leal, Teatro bufo, siglo XIX. Antología, La Habana, 1975. Como ejemplos de la utilización lingülstica de estos textos, véanse J. García González, R. Reyes Perera, L. Alfaro Echevarría y S. Carreras Gómez, «Algunos fenómenos morfosintácticos en textos populares cubanos del siglo XIX*, en Islas (Santa Clara), 77, 1984, págs. 61.76 y, sobre todo, M. Álvarez Nazario, El elemento afronegroide en el español de Puerto Rico, San Juan, 1974 (especialmente las págs. 383-389 en que se reproduce el «juguete cómico» de Rubén C. F. Caballero, La juega de gallos o el negro bozal).

11 Cfr. Philip D. Curtin, The Atlantic Slave Trade. A Census, Madison, 1969 (que siguen siendo monografia básica); Herbert S. Klein, The Middle Passage, Princeton, 1978; James A. Rawley, The Transatlantic Slave Trade. A History, Nueva York, 1981; J. E. Inikori, "Measuring the Atlantic slave trade: an assessment of Curtin and Ansley», en Journal of African History, 17, 1976, págs. 197-223. También el número 226-227 de la Revue Française d'Histoire d'Outre Mer (1975), dedicado monográficamente a la trata de negros a través del Atlántico, y la publicación oficial de U.N.E.S.C.O., La trata negrera del siglo XVI al XX, Barcelona, 1981.

12 Además de los trabajos citados en la nota 9, referidos al área dominicana, véanse, para Cuba, F. Knight, Slave Society in Cuba during the Nineteenth Century, Madison, 1974; V. Martinez Alier, Marriage, Class and Colour in Nineteenth-Century Cuba, Cambridge-Londres, 1979 y Jose Luciano Franco, Comercio clandestino de esclavos, La Habana, 1980 y, también para Santo Domingo, Carlos Esteban Deive, La esclavitud del negro en Santo Domingo, Santo Domingo, 1980. 
tiempo por Kany ${ }^{13}$ y más recientemente ( $y$ con diferentes matizaciones) por otros estudiosos ${ }^{14}$, que reclama la toma en consideración (al menos como concausa en un proceso de causación múltiple) de un factor determinador africano en la génesis del rasgo sintáctico caribeño que aquí analizamos.

No ignoro que, en el momento actual, un punto de vista como el que acabo de exponer es susceptible de provocar reticencias y oposiciones frontales asentadas no sólo en (inconfesadas pero, sin embargo, actuantes) actitudes psicológicas de matiz europeocéntrico o, mejor, albocéntrico sino, y más abiertamente, en el prestigio de que hoy gozan enfoques teóricos que, descartando, un tanto apriorísticamente, las posibles consecuencias de la interacción histórica de fuerzas, sectores y grupos sociológicos, encuentran más adecuado referir la totalidad, o casi, de los procesos lingüísticos de cambio a condicionamientos internos del sistema o, en su caso, a la incidencia sobre fenómenos concretos del mismo de factores tipológicos o derivas estructurales de indole abstractamente universalista ${ }^{15}$.

Tampoco me son desconocidas determinadas posturas de menosprecio irónico respecto a la posibilidad de demostrar la existencia, en las lenguas africanas que, por razones históricas, estuvieron presentes en América y pudieron, por ello, influir de algún modo sobre los códigos comunicativos de origen europeo del Nuevo Continente, de un lowest common denominator que, superando la supuesta absoluta heterogeneidad primaria de aquéllas pudiera dar lugar a una explicación lógica de cómo algunos de sus rasgos gramaticales o fónicos han podido transferirse al inglés, español o portugués americanos ${ }^{16}$.

Respecto a este último punto $\mathrm{y}$, específicamente, respecto a los propugnadores del "enfoque teórico" al que me acabo de referir, es preciso deducir de sus manifestaciones que no sólo ignoran los datos más elementales referidos a la fundamentación teórica de la clasificación de las lenguas africanas (y, más concretamente, de las enclavadas en las zonas occidentales del Continente Negro que fueron, históricamente, las que pudieron tener presencia colectiva en América) en familias, ramas y grupos ${ }^{17}$, lo que implica, de modo

\footnotetext{
13 Charles F. Kany, American-Spanish Syntax, Chicago, 1945 (pág. 125).

14 Entre ellos W. W. Megenney en su estudio $\$ \mathrm{La}$ influencia criollo-portuguesa en el español caribeño*, en Anuario de Lingǘstica Hispánica, 1, 1985, págs. 157-179.

15 Como un ejemplo de esta actitud metodológica, véase el (por otra parte muy valioso) trabajo de Rafael A. Núñez Cedeño, «Pérdida de transposición de sujeto en interrogativas pronominales del español del Caribe*, en Thesaurus, 38, 1983, págs. 35-58.

16 Véase, por ejemplo, D. Bickerton, Dynamics of Creole System, Cambridge, 1975, pág. 58.

${ }_{17}$ Acerca de este complejo tema véanse, ante todo, las fundamentales monograflas de J. H. Greenberg, Studies in African Linguistic Classification, New Haven, 1955 y The Languages of Africa, Bloomington, $1963 \mathrm{y}$, en un segundo plano, también I. Fodor, The Problems of Classification of African Languages, Budapest, 1966. Acerca de la fa-
} 
lógico, la existencia en ellas de rasgos gramaticales (no sólo léxicos) comunes a extensas áreas lingüisticas, sino que desconocen, del mismo modo, los estudios, de indole tipológica ${ }^{18}$, de fundamentación sociohistórica ${ }^{19} \mathrm{o}$ de carácter simplemente empírico ${ }^{20}$, que se han venido realizando en los últimos decenios y que demuestran, con todo el rigor cientifico exigible, la presencia, tanto entre como dentro de los grupos lingüísticos negro-africanos de rasgos estructurales compartidos que permiten, sin lugar a dudas (más o menos sarcásticas), establecer determinaciones areales univocas respecto a los mismos.

Esto es lo que ocurre en concreto, en relación con numerosos fenómenos gramaticales, con las lenguas negro-africanas de la costa occidental, tal como lo recordaba recientemente uno de sus mejores conocedores, David Dalby ${ }^{21}$, $\mathrm{y}$, aún más específicamente, respecto al fenómeno que aquí nos interesa.

En efecto, William E. Welmers ${ }^{22}$ hace notar que, a partir de datos de lenguas como el fante, kpelle, igbo, efik, yoruba, luganda, kikóongo y swahili, se puede establecer una estructura común (ampliable a la totalidad de las lenguas de la familia Níger-Kongo) para la expresión de la interrogación, tanto abierta como cerrada, consistente en la alteración del esquema tonal de la frase asertiva homóloga y/o la utilización de elementos nominales, independientes o dependientes ${ }^{23}$, situados en segmentos fijos, diferentes para cada lengua, de la estructura interrogativa. En ninguna de las lenguas de la familia lingüistica Niger-Kongo se ha identificado, para la expresión de la interrogación, el uso de la inversión o alteración del orden de palabras de la oración asertiva lo que, lógicamente, se aplica también a la posición del elemento marcador de sujeto ${ }^{24}$.

milis lingǘstica Niger-Kongo, cfr. D. Westermann, Die westlichen Sudansprachen und ibre Beziebungen zum Bantu, Berlín, 1927 (2:" edición Londres, 1949).

18 Por ejemplo, B. Heine, «Language typology and convergence areas in Africa», en Linguistics, 144, 1975, págs. 27-47.

10 Cfr. Charles Gilman, «African areal characteristics: Sprachbund, not substrate?», en Journal of Pidgin and Creole Languages, 1, 1986, págs. 33-50.

20 William E. Welmers, African Language Structures, Berkeley, 1973.

21 «In terms of vocabulary, there is a great diversity among these languages [West African] but, interestingly enough, there is frequently much less divergence in terms of their structures or linguistic systems. Adjacent languages employing substantially different vocabularies are often strikingly similar in terms of their sound systems, grammatical systems and semantic systems», cit. en Douglas-Val Ziegler, «Be-Twi-n the lines: Some Akan linguistic influence in the New World», en Antbropological Linguistics, 23 (5), 1981, págs. 203-208 (pág. 203).

22 Obra citada en la nota 20, págs. 416-445.

23 Empleo aqui la terminologla gramatical utilizada por la escuela francesa de africanistas. Cfr. Pierre Alexandre, Manuel élementaire de la langue bulu, Paris, 1956.

24 Cfr. sobre este punto, tanto la obra de Welmers citada en la nota 20 como la ya clásica de Frederick W. Migeod, The Languages of West Africa, Londres, 1971, y, 
Así, por ejemplo, en yoruba yío wà (él vendrá) - yío wà bi (¿ vendrá él ?); en ewe é va (él vino) - é vâ (¿vino él?); en kikóongo weti kwè: ndà wưnù (tú viajas hoy) - weti kwé: ndà wúnú (¿ viajas hoy?); en fante òrikása (¿ quién está hablando?) frente a la misma forma léxica compleja, con esquema tonal diferente, que significa 'él está hablando' 25 . Por su parte, en bulu, juntamente con la modificación del esquema tonal de la frase asertiva, se utilizan como elementos indicadores de interrogación /ye/o / gǵà/ en las preguntas cerradas y los nominales dependientes /-vé/ o /-ánémbé/ y los independientes /je/, /zá/, /bezá/, /ayá/ o /vé/ en las abiertas ${ }^{26}$.

Como era, desde luego, de esperar, las hablas criollas africanas de léxico europeo comparten las pautas configuradoras de la interrogación que se dan en la totalidad de las lenguas aborigenes del Africa occidental.

Aquellas modalidades criollas que poseen, como elemento fonológico, rasgos tonales silábicos, los emplean del mismo modo que las lenguas negroafricanas que les son más próximas geográfica y/o sociolingüisticamente. Así, en el criollo de léxico inglés de Camerún "a change in intonation is often the only signal that a statement has become a question" $n$.

En aquéllas en las que el rasgo constituído por el tono silábico no tiene (o, al menos, no tiene formalmente sino sólo en pares léxicos aislados) valor fonológico, como ocurre en las hablas criollas de léxico portugués del Africa occidental, la expresión de la interrogación se realiza mediante la modificación de la curva tonal de la frase homóloga asertiva y/o mediante el uso de elementos léxicos adecuados. Pero en ningún caso (y lo mismo ocurre en las hablas criollas africanas de léxico inglés) se utiliza para ello la inversión o, en general, la alteración del orden de palabras de una frase asertiva.

En annobonés "el sujeto se coloca delante del verbo, sea que éste esté en forma positiva, negativa o interrogativa ..." 28 :

¿Bo gongó ua guésa? (¿ tú quieres ver la iglesia?) ${ }^{29}$.

${ }_{i}$ Bo bi tempu longo za? (¿hace mucho que has llegado?) ${ }^{30}$.

Iguales pautas sintácticas se dan en el criollo de São Tomé en el que, sin embargo, están presentes elementos fónicos finales específicos, marcado-

\footnotetext{
para las lenguas bantu, K. Meinhof, Grundzüge einer vergleichenden Grammatik der Bantusprachen, Hamburgo, 1948.

28 W. E. Welmers, obra citada en la nota 20 , pág. 435.

26 P. Alexandre, Système verbal et prédicatif du bulu, Parfs, 1966, págs. 130-132.

27 Loreto Todd, Modern Englishes. Pidgins and Creoles, Oxford, 1984, pág. 138.

28 Natalio Barrena, Gramática annobonesa, Madrid, 1957, pág. 84. Mis propios trabajos de campo sobre el annobonés confirman la justeza de esta observación del padre Barrena.

${ }^{20}$ Obra citada en la nota anterior, pág. 87.

30 Obra citada en la nota 28 , pág. 88 .
} 
res del sentido interrogativo de la frase, que no se emplean en annobonés (ni en principense $\mathbf{y}$ caboverdeano) :

d'äji bo ka ta $n$-e? (¿ dónde vives?) ${ }^{31}$.

¿nãse ku'me za? (¿ya comisteis?) ${ }^{32}$.

¿'ã $j i$ e pe ka'fe? (¿dónde puso él el café ?) ${ }^{33}$.

En Cabo Verde existen los mismos elementos conformadores de la expresión interrogativa que en Annobón (y en Principe):

¿purke bo pagá lum? (¿ por qué apagas la luz?) (Islas de Barlovento). ¿pamodi bo paga lumi? (¿ por qué apagas la luz?) (Islas de Sotavento) ${ }^{34}$. ¿dondê kĕ bô stâ? (¿dónde estás tú?).

¿đdondê kĕ bô $t(\breve{e})$ tâ bê? (¿̇ de dónde vienes?) ${ }^{35}$.

¿kza $\hat{e}$ ke bô kõmprâ? (¿ qué compraste?) ${ }^{36}$.

Más sorprendente y, por ello, más significativo es que (en expresión de P. Muhlhäusler) "the 'luxury' of different word order" ${ }^{37}$ en relación con las frases interrogativas, es decir, la inversión de la posición del pronombre sujeto propia de las oraciones asertivas para expresar este contenido significativo, no se dé tampoco, en ningún caso, en las diferentes hablas de tipología criolla (ya sea su léxico de origen inglés, francés, portugués o español) que existen en territorio americano.

Asi, en el gullah del sur de los Estados Unidos, “in interrogative sentences the Gullah speaker usually places the subject before the verb just as he does in declarative sentences... In many instances the question can be distinguished from the statement by the intonation, but not always" ${ }^{38}$, del mismo modo que ocurre en el criollo jamaicano o en el sranan de Guyana ${ }^{39}$.

3 Luiz Ivens Ferraz, The Creole of São Tomé, Johannesburg, 1979, pág. 64.

* Obra citada en la nota anterior, pág. 65.

a Obra citada en la nota 31, pág. 72.

a Luiz I. Ferraz y Marius Valkhoff, \&A comparative study of São-Tomense and Cabo-Verdiano creole», en Marius F. Valkhoff (ed.), Miscelanea luso-africana, Lisboa, 1975, págss. 15.39 (pág. 25).

35 Baltasar Lopes da Silva, O dialecto crioulo de Cabo Verde, Lisboa, 1984, pág. 169.

36 Obra citada en la nota anterior, pág. 165.

37 Peter Mühlhäusler, Pidgin and Creole Linguistics, Oxford, 1986, pág. 156.

38 Lorenzo D. Turner, Africanisms in the Gullab Dialect, Ann Arbor, 1974, pág. 218.

30 Cfr. John Holm, Pidgins and Creoles, I, Cambridge, 1988, págs. 213-214. 
Similar situación se da en el papiamento:

${ }_{6}$ Bo tin buki na papiamentu? (¿tiene usted libros en papiamento?) ${ }^{40}$. ¿Qué cosa bo quier comé? (¿qué quieres comer?) ${ }^{41}$.

Y lo mismo puede decirse del créole haïtien:

¿Ak ki mun $u$ zwé? (¿Con quién juegas?).

Por lo que se refiere a la modalidad criolla, de léxico español, de San Basilio de Palenque (Colombia), "Las preguntas... tienen en el vernáculo una estructura interna diferente de la que poseen en el español colombiano: el término interrogativo va seguido obligatoriamente del sujeto expreso y después viene el verbo". O sea:

- Palenquero: Interrogativo - Sujeto - Verbo.

- Español colombiano: Interrogativo - Verbo - (Sujeto)":

Nina joke bo tre mi? 'Nina ¿y qué me traes?'.

${ }_{\text {¿Ke }}$ utere á sé tá buká? '¿qué están buscando (ustedes)?'.

${ }_{i} \mathrm{Ke}$ bo tan ndá fulano? '¿y qué le vas a dar a fulano?' ${ }^{42}$.

${ }_{¿} K e$ enú tá asé? '¿qué están haciendo ustedes?'.

¿Kwanto utere ten? '¿y cuánto tienen ustedes?' ${ }^{43}$.

Hasta aqui hemos podido constatar que la totalidad de las lenguas aborígenes del Africa Negra occidental y también, sin excepción, las hablas de tipología criolla y léxico europeo que se manejan tanto en los territorios del oeste de Africa como en la América tropical y subtropical desconocen el uso de la alteración del orden de palabras de la frase asertiva para expresar la interrogación o, en otras palabras, no emplean la inversión de posición del sujeto (pronominal o nominal) para este fin, a diferencia de lo que ocurre, con carácter de generalidad, tanto en el español, francés y portugués europeos como en inglés estándar ${ }^{4}$.

40 Orlando Ferrol, La cuestión del origen y la formación del papiamento, La Haya, 1982, págs. 57-58.

41 Artículo de W. W. Megenney citado en nota 14, págs. 173-174.

42 Carlos Patiño, «El habla en el Palenque de San Basilio», en Nina S. de Friedemann y Carlos Patiño, Lengua y Sociedad en el Palenque de San Basilio, Bogotá, 1983, pág. 144.

4s Obra citada en la nota anterior, pág. 161.

4 Véase, sin embargo, para el francés, M. Harris, «The inter-relationship between phonological and grammatical changew, en J. Fisiak (ed.), Recent Developments in Historical Phonology, La Haya, 1978, págs. 159-172. 
Pero la extensión del fenómeno en cuestión en tierras americanas no se ciñe a los casos, que hasta ahora hemos considerado, de códigos lingüísticos criollos. En efecto, además de en el área del Caribe hispánico, se puede constatar la inexistencia de la inversión del sujeto como marca de interrogación en varias modalidades lingüísticas de códigos de comunicación de origen europeo empleadas en diferentes zonas del Nuevo Continente.

Así, el denominado portugués popular brasilero (PBP) "lack subject inversion in questions: compare PBP onde você mora?... which is paralleled in the creoles but not found in Portuguese of Europe, where subject-verb inversion requires onde mora você? or onde é que você mora?" 45 .

Similar situación se da, como ya notó hace muchos años T. Navarro Tomás ${ }^{46}$, en algunas modalidades del inglés dialectal empleado en zonas del Sur de los Estados Unidos y en el Black English ${ }^{47}$. Y, del mismo modo, en el inglés manejado por grupos sociológicos caribeños de raza blanca que habitan en pequeñas comunidades aisladas y altamente homogéneas desde el punto de vista social (Island Harbour en Anguilla, Scotland District en Barbados, Mount Moritz en Grenada, Mount Pleasant en Bequia, Hells Gate o Wiindwardshire en Saba, Dorsetshire Hill en San Vicente). En estas variedades lingüisticas, en efecto, se da "unaltered word order in interrogative constructions: why you can't do it? (Saba), where you's from? (Saba)" según Jeffrey $\mathrm{P}$. Williams ${ }^{48}$ cuyo testimonio es de más valor aún si se tiene en cuenta que su postura teórica respecto a la caracterización del inglés caribeño no es, precisamente, favorable a la tesis del influjo en él de rasgos de procedencia (directa o indirecta) africana tal como ha sido mantenida, entre otros especialistas, por $\mathrm{J}$. Holm ${ }^{49}$.

De los datos empíricos que, de modo voluntariamente muy conciso, hemos presentado en los párrafos anteriores, se deducen, a mi modo de ver, algunas conclusiones dificilmente discutibles.

Es la primera la comprobación de que la no inversión de la posición del pronombre sujeto en oraciones interrogativas propia del español empleado

4s John Holm, «Creole influence on Popular Brazilian Portuguese», en Glenn G. Gilbert (ed.), Pidgin and Creole Languages. Essays in Memory of Jobn E. Reinecke, Honolulu, 1987, págs. 406-429 (pág. 414).

46 T. Navarro Tomás, El español en Puerto Rico, Río Piedras, 1948, pág. 132, nota 1.

17 Cfr. W. Labov, P. Cohen, C. Robins y J. Lewis, A Study of the Non-Standard English of Negro and Puerto Rican Speakers in New York City, Nueva York, 1968 y W. Labov, Language in the Inner City. Studies in the Black English Vernacular, Philadelphia, 1972. También J. L. Dillard (ed.), Perspectives on Black English, La Haya, 1975 y M. C. Alleyne, Comparative Afro-American, Ann Arbor, 1980.

48 *Preliminaries to the study of the dialects of White West Indian English*, en Nieuwe West-Indische Gids, 59, 1985, págs. 27-44 (pág. 41).

40 *African features in White Bahamian English", en English World-Wide, 1, 1980, págs. $45-65$. 
en el Caribe hispánico no constituye un hecho aislado sino que, muy al contrario, se inserta en un conjunto homogéneo de fenómenos similares que abarca las lenguas aborígenes africanas occidentales, las variedades criollas de léxico europeo del oeste de África y de la América tropical y determinadas modalidades de lenguas históricas europeas manejadas, igualmente, en la América tropical o subtropical (portugués popular brasileiro, inglés "blanco" del Caribe y del Sur de los Estados Unidos, Black English).

En segundo, y muy importante, lugar se impone, creo, la convicción de que hay un solo factor común a los códigos lingüisticos que, según la enumeración que acabamos de realizar, poseen el rasgo sintáctico que aquí analizamos (no inversión de la posición del sujeto, pronominal o nominal, en oraciones interrogativas): su relación, bien por la situación geográfica (hablas criollas de léxico europeo del Africa occidental), bien por sus procesos genéticos y componentes estructurales (hablas criollas de léxico inglés, francés, portugués o español de la América tropical) o por sus contactos areales (portugués popular brasileiro, español del Caribe, inglés "blanco" de los Estados Unidos o de las pequeñas Antillas), con modalidades de lenguas enclavadas o procedentes del Africa occidental y finalmente, y de modo obvio, se constata que, en cuanto a los diferentes casos de uso del rasgo lingüístico que estudiamos referidos a lenguas europeas habladas en América, su empleo difiere de las pautas sintácticas aplicadas no sólo en las modalidades estándar de las mismas sino también, casi sin excepción, en el resto de sus variedades diatópicas europeas y americanas.

De todo lo hasta aquí apuntado parece deducirse, inevitablemente, un claro corolario referido a la génesis del rasgo sintáctico de la no inversión de la posición del sujeto, pronominal o nominal, en las oraciones interrogativas que se encuentran en variedades lingüísticas diatópicas (criollas o no) del área territorial americana.

El mismo puede ser expresado, en un ámbito genérico, postulando para el fenómeno en cuestión un condicionamiento causal relacionado (a través de procesos, diferenciados, de derivación histórica o de contacto areal) con la presencia del mismo en las lenguas negro-africanas occidentales pertenecientes a la familia lingüística Niger-Kongo.

Por lo que se refiere, más concretamente, al español del Caribe hispánico pienso que el rasgo sintáctico a que aquí nos referimos pudo ser difundido en el área antillana, de acuerdo con un modelo dinámico bien conocido y estudiado teóricamente ${ }^{50}$, desde los estratos inferiores de las sociedades locales constituidos, muy mayoritariamente, por grupos sociológicos, negros o mulatos, de procedencia africana. Estos grupos habrían conservado, bien

so Cfr. A. Kroch, *Towards a theory of social dialect variation», en Language in Society, 7, 1978, págs. 17.36. 
en los interlectos específicos del español originados en diversas $L_{1}$ africanasoccidentales ${ }^{51}$, bien en las variantes, progresivamente descriollizadas, de modalidades criollas previas de base, también, africana occidental ${ }^{52}$, el fenómeno sintáctico de la no inversión de la posición del sujeto en oraciones interrogativas ${ }^{53}$ y lo habrían transmitido, a su vez, al habla de otros estratos sociológicos locales con los que tenían contactos amplios y prolongados, dando, así, origen a un proceso de difusión vertical, cada vez más amplio y abarcador, que parece no haber culminado, según se trasluce al menos de imprecisos datos expuestos por Henríquez Ureña ${ }^{54}$, en algunas zonas hasta las primeras décadas del siglo $\mathrm{xx}$ con la adopción del mismo por los estamentos sociales superiores y las élites locales que hasta entonces habrian utilizado (quizá en contextos caracterizados por su formalidad) el esquema sintáctico, estándar, de procedencia metropolitana.

La posición teórica por mí propugnada no es, sin embargo, excluyente respecto a otros puntos de vista que han sido mantenidos, hasta ahora, por diferentes especialistas.

51 Acepto en este punto la postura teórica planteada por H. López Morales en su trabajo «Sobre la pretendida existencia y pervivencia del 'criollo' cubano", en Anuario de Letras, 17, 1980, págs. 85-116 y, en ese sentido, no tengo inconveniente en suponer que hablantes de lenguas africanas llevados a Cuba y Puerto Rico como esclavos llegaban a manejar el español a través de una serie de interlectos progresivamente más próximos a la $\mathrm{L}_{2}$. Pero considero que este hecho es compatible con la existencia en Cuba de otros grupos de africanos que adquirieron el uso del español local como resultado de procesos de descriollización del tipo de los postulados por mí mismo y por otros especialistas. Cfr., en este sentido, M. Perl, «Las estructuras de comunicación de los esclavos negros en Cuba en el siglo xIX», en Islas, 77, 1984, págs. 43-59; «Habla bozal-eine-basierte Kreolsprache?», en M. Perl (ed.), Beiträge zur Afrolusitanistik und Kreolistik, Bochum, 1989, págs. 17-31 y «Zur Morphosyntax der Habla Bozal», en Vielfalt der Kontakte. Beiträge zum 5. Essener Kolloquium über «Grammatikalisierung, Natürlicbkeit und Systemökonomie», I, Bochum, 1989, págs. 81-94.

${ }_{52}$ Cfr. mi trabajo «Algunos datos sobre la pervivencia del criollo en Cuba», en Bo. letín de la Real Academia Española, 51, 1971, págs. 481-491. También M. Perl, «El fenómeno de descriollización del habla bozal y el lenguaje coloquial de la variedad cubana de español», en Anuario de Lingüística Hispánica, 1, 1985, págs. 191-201 y DouglasVal Ziegler, «A preliminary study of Afro-Cuban Creole» (estudio aún inédito).

ss Y también en otros casos (en construcciones de infinitivo, tras $a l$, sin y por, etc.). Véanse, sobre el tema, Amparo Morales de Walters, «Infinitivo con sujeto expreso en el español de Puerto Rico», en R. M. Hammond y M. C. Resnick (eds.), Studies in Caribbean Spanish Dialectology, Washington, 1988, págs. 85-96; M. Suñer, «Lexical subjects in infinitives in Caribbean Spanish», en O. Jaeggli y C. Silva-Corvalán (eds.), Studies in Romance Linguistics, Dordrecht, 1988, págs. 183-196 y E. Torrego, «On inversion in Spanish and some of its effects», en Linguistic Inquiry, 15, 1984, págs. 103-129.

54 En las primeras décadas del siglo xx (antes de 1930) aún existían en Santo Domingo grupos sociales, muy probablemente identificables con los estratos superiores de la ciudad capital, que no empleaban el esquema interrogativo caribeño (hoy general) sin inversión del pronombre sujeto. El mismo Henríquez Ureña suponf́a que este último uso podría haber entrado en Santo Domingo, desde Cuba, en fechas relativamente recientes. Véase P. Henriquez Ureña, El español en Santo Domingo, Buenos Aires, 1940, pág. 232. 
Es cierto que algunas de las hipótesis emitidas en relación con la no inversión de la posición del sujeto (pronominal o nominal) en oraciones interrogativas en el área del Caribe hispánico me parecen desprovistas, por diversos motivos, de verosimilitud. Así ocurre, por razones simultáneamente históricas y sociodemográficas, con las posturas mantenidas por T. Navarro Tomás ${ }^{55}$ y por Tomás Buesa ${ }^{56}$, quienes atribuyen, respectivamente, el rasgo caribeño en cuestión al influjo de esquemas sintácticos del inglés popular del sur de los Estados Unidos y al del castellano del noroeste peninsular. $\mathrm{O}$ en otro aspecto, y por consideraciones de inadecuación objetiva a los datos empíricos conocidos, con los enfoques del tema presentados por J. C. Davis (incidencia del acento rítmico) ${ }^{57}$ y por J. J. Bergen (tendencia a la anteposición o postposición de elementos léxicos mono o polisilábicos respecto al verbo) ${ }^{58}$.

Pero, por el contrario, considero que representan factores condicionantes adecuados del rasgo antillano que aqui estudiamos (si bien con diversos grados de aplicabilidad al mismo), tanto las posibilidades de analogía sintáctica expuestas por R. Lapesa ${ }^{59}$, la hipótesis funcional ${ }^{60}$ o la interferencia sintagmática de conglomerados léxicos propugnada por J. M. Lipski ${ }^{61}$, todos ellos incluibles dentro del funcionamiento específico del código lingüístico español, como la aproximación a determinados esquemas de la sintaxis natural propugnada por B. Stiehm ${ }^{62}$ o la tendencia a la generalización del orden de palabras SVO señalada por Amparo Morales ${ }^{63}$, en el ámbito de fenómenos generales de indole tipológica.

Aplicando al tema concreto que estudiamos una útil distinción teórica expuesta por J. Vachek ${ }^{64}$, creo que todos los factores condicionantes que acabo de mencionar participan, junto, quizá, con algún otro de índole ex-

\footnotetext{
So Loc. cit. en nota 46.

s6 *Anotaciones sobre regionalismos peninsulares en el español de América», en Boletin de la Asociación Europea de Profesores de Español, 34-35, 1986, págs. 107-126.

ه7 *Tú, ¿qué tú tienes?», en Hispania, 54, 191, págs. 331-333.

so *The explored and unexplored facets of questions such as ¿qué tú tienes? , en Hispania, 59, 1976, págs. 93-99.

so En el estudio citado en la nota 1.

60 Pero véanse las observaciones, sumamente escépticas, que, respecto a este posible factor causal del fenómeno que aqui examinamos, expresa Amparo Morales de Walters en su trabajo «Hacia un universal sintáctico del español del Caribe: el orden SVO», en Anuario de Lingüística Hispánica, 5, 1989, págs. 139-152.

61 «Preposed subjects in questions: some considerations», en Hispania, 60, 1977, págs. 61-67.

62 * Sintaxis histórica, dialectos de América y sintaxis natural», en Actas del Primer Congreso Internacional sobre el Español de América, San Juan, 1987, págs. 441-447.

*s Estudio citado en la nota 60.

* $\mathrm{On}$ the interplay of external and internal factors in the development of language», en Lingua, 11, 1962, págs. 433-448.
} 
terna cuya toma en consideración no me parece todavía absolutamente clara ${ }^{65}$, en el origen causal del rasgo sintáctico antillano que nos ocupa mientras que su proceso genético debe ser atribuido, explícitamente, a la progresiva incorporación al sociodiasistema del español caribeño de un esquema sintáctico originado, primariamente, en la transferencia a los sociolectos inferiores del mismo de pautas sintagmáticas de procedencia africana a través, posiblemente, de procesos, convergentes, de formación de interlectos afro-españoles ${ }^{60}$ y de descriollización local.

65 Me refiero, concretamente, a la incidencia, en la producción del fenómeno sintáctico caribeño que aquí analizamos, de un posible factor causal identificable con la presencia en las Antillas, como inmigrantes, de hablantes de modalidades dialectales canarias en las que existirfa el empleo del rasgo en cuestión.

Confieso que los datos recopilados por M. Álvarez Nazario (en La berencia lingüística de Canarias en Puerto Rico, San Juan, 1972, pág. 94 y en «Relaciones históricodialectales entre Puerto Rico y Canarias», en I Simposio Internacional de Lengua Española, Las Palmas, 1981, págs. 289-310) no me parecieron suficientes para atestiguar la vitalidad de la no inversión de sujeto en oraciones interrogativas en las hablas del Archipiélago Canario y, lógicamente, tampoco para demostrar la relevancia del condicionamiento genético representado por la posible transferencia de dicho rasgo, desde alguno de los subdialectos canarios, al español caribeño.

Me ha hecho pensar de otro modo el dato, dado a conocer recientemente por John M. Lipski (en The Language of the Isleños. Vestigial Spanish in Louisiana, Baton Rouge, 1990 , págs. 39-42), de que en el habla de los «isleños», de origen canario, de Louisiana está presente, con gran vigor, el uso de la no inversión del sujeto en frases interrogativas, lo que, dada la fecha (siglo xviII) de fundación de los enclaves canarios en Louisiana, podría hacer suponer la existencia, durante este perfodo temporal, en las hablas canarias metropolitanas de un grado de vitalidad respecto al fenómeno sintáctico en cuestión que hoy no se da.

No obstante, la posibilidad de que el rasgo de que aquí nos ocupamos proceda, en el español de los «isleños» de Louisiana, bien de un proceso de fijación y rigidificación de pautas sintácticas, propio de los estadios previos a la desaparición de una lengua (cfr. N. C. Dorian, Language Death: the Life Cycle of a Scottish Gaelic Dialect, Philadelphia, 1981), bien del contacto histórico con modalidades del créole louisianais (gombo) en posesión de esquemas sintácticos interrogativos sin inversión de sujeto me hace suspender, por ahora, el juicio sobre el tema.

* Sobre el concepto teórico de interlecto, véase L. Selinker, «Interlanguage», en International Review of Applied Linguistics, 10, 1972, págs. 209-231. 